\title{
EDUCAR PARA LA EVOLUCIÓN DE LA VIDA HUMANA Y PLANETARIA. UNA PERSPECTIVA COMPRENSIVO EDIFICADORA
}

\section{EDUCATING FOR THE EVOLUTION OF LIFE HUMAN AND PLANETARY. A COMPREHENSIVE BUILDING PERSPECTIVE}

\author{
Julio César Arboleda ${ }^{2}$ \\ direccion@redipe.org
}

$1 \quad$ Este artículo representa una adecuación del Capítulo 4 del libro: Enseñar educando. Hacia una didáctica comprensivo edificadora. Arboleda, J. C (2020). Igualmente fue presentado como Conferencia central del VII Congreso Internacional RIDECTEI organizado por la Universidad Complutense de Madrid y Redipe, Red Iberoamericana de Pedagogía, 7/9 de mayo de 2020. https://youtu.be/qKJaTHyJ1p8 y doctorado en Educación. Grupos de investigación Redipe y Educación y desarrollo humano, USB. Directorcientífico de Redipe. Creador de la perspectiva comprensivo edificadora de la educación, la pedagogía y la didáctica, y de la pedagogía por proyectos de vida, que incluyen aportes teóricos y metodológicos. direccion@redipe.org Orcid: ttps://orcid.org/0000-0002-1572-5384

Google scholar:

https://scholar.google.com/citations? user=xeClbeYAAAA$\underline{J \& h l=e s}$

\section{RESUMEN}

En este documento se reflexiona de manera crítica y propositiva en torno a la necesidad de repensar con mentalidad comprensivo edificadora, civilizatoria, las conceptualizaciones y prácticas educativas contemporáneas. Se hace particular énfasis en la manera como estas prácticas, al compás rítmico de los criterios e índices que apalancan el progreso socioeconómico (que se aprovecha y a veces 
inspira hasta el delirio el avance tecnocientífico), eufemísticamente acuñado bajo la expresión "desarrollo humano", se alejan cada vez de los principios originarios y más sentidos de la educación y la pedagogía.

No es posible educar bajo criterios de progreso humana y existencialmente involutivos, como los que impone la modernidad capitalista. Se educa para un desarrollo social humanizado, que aporte sustantivamente a la evolución de la vida humana y planetaria. En aras de aportar al esclarecimiento del lenguaje relacionado con la acción de educar se proponen resignificados definitorios de conceptos tales como pedagogía, educar, desarrollo humano, vida, humanización, humanización de la educación, enseñar educando, comprensión edificadora, comprensión ética, entre otros.

\section{SUMMARY}

This document reflects critically and purposefully on the need to rethink, with a comprehensive edifying, civilizing mentality, contemporary educational conceptualizations and practices. Emphasis is placed on the particular way in which these educational processes, to the swaying of criteria and indices that leverage socioeconomic progress (which takes advantage of and sometimes inspires even delirium of technoscientific progress, and which has been coined under the euphemism "human development") are increasingly distancing themselves from the original and more meaningful principles of education and pedagogy.

It is not possible to educate under criteria of human progress and existentially involutives, such as those imposed by capitalist modernity. We educate for a humanized social development that contributes substantially to the evolution of human and planetary life. In order to contribute to the clarification of the language related to the action of education, it is proposed to re-definitive meanings of concepts such as pedagogy, education, human development, life, humanization, humanization of education, teaching by educating, edifying understanding, ethical understanding, among others.

KEY WORDS: educating, edifying understanding, ethical understanding, evolution of life, otherness.

\section{INTRODUCCIÓN}

El propósito de esta exposición es aportar, desde la perspectiva comprensivo edificadora, al esclarecimiento y resignificación del concepto educar, y de las acciones mínimas que, para corporizarlo como acto situado, se espera realicen las instituciones, en particular la escolar y los agentes encargados de esta función.

Inicialmente se propone una definición que intenta abarcar los consensos que hay respecto al acto de educar, con un valor diferencial: se plantean reconceptualizaciones de algunos subconceptos explícitos o implícitos en la misma, entre otros: vida, pluridimensionalidad humana y pluriversidad de la existencia, enseñanza, enseñar educando y humanización, comprensión ética y edificadora.

Luego, se presentan generalidades de la perspectiva comprensivo edificadora, con los conceptos comprensión, nivel edificador, comprensión edificadora y la metáfora del parto pedagógico formativo, propuestas mediante las cuales se explicita el concepto y la función de educar, el acogimiento como principio pedagógico y las enseñanzas que educan para formar sujetos, ciudadanos del pluriverso, es decir seres comprensivo edificadores que asumen la responsabilidad ética de usar sus comprensiones para la evolución de la vida humana y planetaria.

\section{LA ACCIÓN EDUCATIVA Y LA FUNCIÓN DE EDUCAR}

Educar es el acto por el cual se generan 
oportunidades y potenciales para la formación de sujetos que usen sus comprensiones y potenciales a favor de su crecimiento como persona y de la evolución de la vida humana y planetaria.

La función de educar que compete a la institución educativa constituye un acto inédito y fallido en los saberes y practicas educativas. Educar es una de las finalidades que en el desarrollo de sus funciones tienen las instituciones sociales (ahí la familia, la educación, la iglesia y los medios de comunicación) para satisfacer las necesidades fundamentales de la comunidad. En la esfera educativa en la que nos concentramos aquí, 'generalmente los encargados de tal función no la asumen idoneamente, entre otras razones por desconocimiento, formación inadecuada o porque se entregan a demandas que les imponen determinadas instancias. La entidad educativa reduce cada vez sus funciones a generar enseñanzas con criterio más técnico que educativo. Interesa más cumplir con estándares mediatizados a través de formatos y protocolos alineados a políticas globales que difícilmente pueden responder a contextos y necesidades localizadas. En estos térmiinos la enseñanza no logra desarrollar intervenciones situadas que promuevan la comprensión consciente de conocimientos, saberes, valores y actitudes; enseñanzas que eduquen y no solo para el aprendizaje de conocimientos; enseñanzas que además de instruir formen, sirvan para ser mejor gente que emplea sus potenciales a favor del entorno y el contorno del hombre, de la vida y la existencia humana y cósmica.

Se educa por y para la vida. En otro momento (Arboleda, 2020 a, b) hemos asumido la vida como el estado en que tiene lugar la evolución de la humanidad y del planeta, la reivindicación del ser vivo e inorgánico, de una existencia más humana, y hacia la cual convergen los derechos fundamentales del hombre, de la tierra y el planeta; y también, de acuerdo con Escobar
(2012), como "el conjunto interminable de formas y entidades que componen el pluriverso — desde lo biofísico a lo humano y lo sobrenatural-y los procesos por los que vienen a ser", lo que va más allá de una preocupación por la 'naturaleza'.

Humanizar la vida, principio supremo del acto educativo, consistiría en generar medios para el cuidado de esta, siendo la pedagogía, campo del conocimiento de la educación que aboga por el cumplimiento de los principios originales y más sentidos de la educación en las posibilidades y decurso de esta actividad (Arboleda, 2011b), el saber que ha de inspirar y liderar la participación escolar y ciudadana al respecto. La humanización es entendida aquí como la actitud favorable a establecer relaciones de existencia en la sociedad ecosistémica, reguladas por los principios de responsabilidad y respeto por la vida, la dignidad humana, el otro y lo otro.

En esta perspectiva la educación cumple su función original si genera oportunidades y potenciales para favorecer un auténtico desarrollo humano y de la vida ${ }^{3}$. En sintonía con esta idea la humanización de la educación consistiría en el acontecimiento deseable mediante el cual se ha de reorientar, bajo preceptos edificantes, las concepciones, ideales y prácticas de los sistemas educativos, de

3 Lo que conocemos como desarrollo humano no es más que un paradigma cuantitativo que supone el crecimiento personal y social a partir del progreso económicotecno-científico. Es un constructo a debe en tanto la vida humana y planetaria es cada vez más erosionada. Las esperanzas de igualdad social y de vida digna se desdibujan a medida que la riqueza se concentra en un sector poblacional cada vez más diminuto, que en razón de la maximización del capital destruye el tejido cósmico. El planeta cada vez es más golpeado debido, sobre todo, a que las urgencias del progreso económico tienen, en este orden político- económico global (léase, colonizante, egocentrista e individualista), mayor prioridad respecto a los derechos del hombre y la Madre tierra. La educación, las practicas y saberes educativos afirman este "desarrollo humano", distanciándose cada vez de su sentido originario. Nuestra perspectiva comprensivo edificadora (CE) de la educación, la pedagogía y la formación apuesta por una educación para la evolución de la vida, para el cuidado y la reconstrucción de los ritmos de la vida humana y planetaria interrumpidos por las razones y emociones despóticas de un mercado destructor, consumidor de vidas. Lo que no es posible sin superar el narcisismo del ensimismamiento, sin cosciencia y sentimiento plural, sin dolencia y responsabilidad ótrica, es decir sin deberse éticamente al otro y a lo otro. 
las disciplinas y asignaturas escolares, de la pedagogía y las ciencias y saberes educativos. La función de educar es el conducto mediante el cual se humaniza el acto educativo.

Se educa para fortalecer los sentidos y proyectos de vida, o proyectos de ser humano del sujeto educable. El acto de educar precisa orientar formaciones para comprender que el actual desarrollo global no es humano porque, como se acaba de expresar, está centrado en y para el crecimiento y el progreso económico, que conviene más a los poderes financieros que al ser humano y la vida, y representa la pulsión de competencia en las diferentes latitudes de la vida social, incluida la educación, como impronta de supuesta prosperidad; no constituye un desarrollo social y planetariamente incluyente, equitativo, respetuoso de los derechos fundamentales del hombre y la tierra. Ha sido un desarrollo para la involución humana, cada vez más egocéntrico, antropocéntrico y desigual, demoledor del planeta y la existencia. Prima en consecuencia una educación, no para el enraizamiento del orden perverso de desarrollo global que estamos caracterizando, sino para la evolución humana, si se prefiere para la formación de ciudadanos comprensivo edificadores que incidan en la reorientación (léase, humanización) del desarrollo social bajo principios edificantes, basado en el respeto a los derechos inalienables que aseguren una evolución sensible.

No se educa al margen de la pluridimensionalidad humana y la pluriversidad de la existencia; se educa para la evolución humana y el desarrollo de la vida. Respecto al ser humano, la verdad monda y lironda es que somos entidades finitas, históricas, inacabadas, contingentes, y estamos siendo. Esa es nuestra gran realidad concreta. Cada individuo humano es una unidad, una unicidad compleja; posee diversas e interdependientes dimensiones, entre otras: física, psíquica, ambiental, social, política, ética, cultural e inclusive digital ${ }^{4}$, cuyo crecimiento redundará en ser mejor persona. Somos seres naturales, sociales, políticos y culturales, y potencialmente éticos, morales, tecno-digitales y ecológicos. Somos complejamente pluriversos. Y seguiremos siendo, en virtud a esta dinámica intestina y a la manera como sigamos afectando nuestras relaciones y nuestro entorno. Educar pasa por acoger, reconocer y potenciar en el educando su pluridimensionalidad, acompañarlo, hasta donde sea posible, para que desarrolle fortalezas sentipensantes, actitudes comprensivo edificadoras en virtud de las cuales logre reafirmar en sus actos sentidos auténticos de, por y para la vida y la existencia humana y cósmica.

En este punto los humanos estamos sometidos a la encrucijada que siembra la metamorfosis del ser: el ser siendo puede recibir el impulso de la educación basada en principios sentidos, o ser suceptible a los constreñimientos que desata el proyecto eficientista de la modernidad, cada vez más incisivo y destructor de humanidad. El individualismo, el consumismo y el rendimiento son los principios que rigen al mundo del mercado que direcciona el orden de la sociedad global, y que se reproducen a través de la educación y los medios de comunicación, entre otras instituciones sociales obligadas a servir el proyecto depredador, rasgando ostensiblemente la evolución dimensional del ser. Por el contrario, la insubordinación de estas y su relocalización en función de sus fines anclados en la humanidad y la vida harían del ser siendo un proceso edificante.

\footnotetext{
$4 \quad$ Con la tecnociencia se ha logrado no solo crear el código genético sino y sobre todo, normalizar, en un acto por lo general de ninguneo ético, la manipulación genética, y con el lenguaje genético digital girando en el vórtice de la vida y la existencia, hemos dejado de ser lo que éramos, y ya somos código textual y matemático introyectado como propiedad característica. Educar en esta dimensión precisa, entre otros aspectos, orientar un uso humanizante de los medios digitales para que aporten al crecimiento pluridimensional, a la transformación del sujeto y a la configuración de nuevas subjetividades e intersubjetividades.
} 
Todo cambio en alguna esfera de su pluridimensionalidad y también en el medio ecosistémico, afecta, para bien o para mal, al individuo, y en general al ser orgánico y al mundo o vida inorgánica; ilustrativo de ello son las crisis ambientales y sanitarias, cuyo impacto en el hombre y en sus relaciones sociales, culturales, ecológicas, económicas y demás, modifica no solo su estado de vida y de existencia, sino también al planeta en su integridad, equilibrio y salud, y por supuesto, al sí mismo del individuo. El confinamiento ha demostrado igualmente que relaciones más sanas con el ambiente tienen cierto efecto de retorno saludable que solo el mismo hombre podría preservar y mejorar, lo que hace del acto de educar una función imperiosa para residir con responsabilidad ética en el globo terrestre.

La vulnerabilidad del orbe toca los más íntimos recodos del ser humano. El hombre es un ser diminuto en el pluriverso, en esa complejidad o encuentro de sistemas vivos y no vivos en incesante relación de interdependencia, interconexión y contingencia. Cada individuo humano es una subjetividad compleja en el intrincado de organismos y seres inertes que moran en el tejido cósmico. Siendo así, somos sujetos humanos, mejor, sujetos pluriversos, frágiles, precarios y necesitados del otro en la relación social y de lo otro en la pluriversidad.

Dada esta realidad, no hay lugar para racionalismos que se eleven por encima de las esferas del contorno humano, ni antropocentrismos que se impongan sobre su entorno, como para creer que la razón es el núcleo de uno mismo y que somos los propietarios, el centro de los ecosistemas; creencia falsa por cierto a través de la cual nos autofacultamos para disponer de unos y otros componentes, afectándolos y afectándonos.

Las crisis sanitarias, humanitarias, económicas, sociales, políticas, educativas, culturales y ecosistémicas a las cuales asistimos, creadas por el hombre bajo un orden supranacional social, económico y político cuya espiritualidad no va más allá de su propia egolatría, por la voracidad de algunos sujetos y grupos para acumular riqueza a través de medios despersonalizantes, y para imponer sus creencias, sus verdades de pretensión absoluta, constituyen un alejamiento del hombre sobre sí mismo como identidad compleja, cambiante; un atentado y desconocimiento sobre la complejidad, léase, la realidad undívaga, conflictiva e incierta de sí mismo, de la vida, la sociedad, la naturaleza y la existencia.

La función de educar encuentra aquí un terreno inhóspito que el acogimiento puede ayudar a animar, y cobra mayor relevancia en estas circunstancias, para formarnos en una consciencia actuante de mundo común, que nos permita proceder en las relaciones sociales y pluriversas con genuino sentido de vida $y$ de existencia, de respeto y cuidado propio, con el otro y con lo otro ${ }^{5}$. En esta función el acogimiento es el sentimiento moral de afectarse por el estudiante como otro, en la singularidad de su existencia, con la obligación ética de hacerse cargo de él. Es este el conocimiento de base sobre el cual ha de actuar la educación, la pedagogía y la didáctica, para orientar la formación de educadores y educandos en el propósito de formar seres más humanos y por ello habitantes dignos del pluriverso.

Entregarse incondicionalmente a la tarea de humanizar la vida y la existencia es el gran reto de la educación, de los saberes que la abordan y demás instituciones sociales, de norte a la conservación de la especie, y por extensión, del cosmos. Humanizar el planeta no significa que el hombre deba asumirse como la médula espinal del mundo, sino como un residente

5 De acuerdo con Ortega (2020, p. 27), creador de la Pedagogía de la alteridad fundamentada en la ética levinasiana, el acogimiento es la "atadura que nos liga irremediablemente al otro", "y que atraviesa la educación de inicio a fin, haciéndose presente en cada uno de sus actos. 
loable, dignidad que se traduce en respeto, cuidado y merecimiento de sí mismo, del otro y de lo otro. En este sentido la función de educar compromete la tarea de humanizar el planeta, de formar personas que comprendan su autorregulación y obren en consciencia de manera edificadora: sepan habitarlo como espacio común, velen por la restauración de la madre tierra, cada vez más vulnerada en sus derechos por la industria de la producciónconsumo y la tecnociencia sometidas al régimen político y financiero.

\section{EDUCAR PARA UNA COMPRENSIÓN QUE EDIFIQUE}

En este aparte se presenta la perspectiva comprensivo edificadora (PCE) de la educación, la pedagogía y la didáctica, que sirve de referente para las conceptualizaciones que ponemos en consideración. Este ejercicio nos permitirá explicitar el mecanismo de la comprensión y el uso sentido de esta, dos aspectos que confluyen como propiedades básicas en el concepto educar.

La PCE es un constructo que tributa a la educación, la pedagogía y la formación reflexiones y medios para educar por y para la vida. Crea escenarios para apropiar, producir, aplicar y usar de manera reflexiva y sentiente conocimientos y potenciales con conciencia actuante condescendiente con la vida, la existencia y el hombre. Hace parte de las perspectivas humanistas y emergentes que generan conocimientos y potenciales (didácticos, curriculares, evaluativos, discursivos, entre otros) dirigidos a vigorizar los acercamientos, prácticas y praxis sobre los procesos interrelacionados de aprender, enseñar y educar. La comprensión edificadora (CE) es el carácter que revisten estos últimos, es decir que los actos de educar, enseñar y aprender son de índole comprensivo edificadora. Para explicitar este concepto y su sentido en el mundo de la educación vamos a tratar de esclarecer una noción de comprensión.

Como finalidad educativa la comprensión no ha sido comprendida de manera cabal (Arboleda, 2005, 2007, 2008, 2011, 2016). Todas las tendencias actuales del lenguaje ponen de manifiesto que las actuaciones de comprensión se reconocen por la disposición y capacidad de los comprendedores para construir significados y sentidos a partir de los objetos de acercamiento. Es decir, que no basta con que alguien entienda un concepto, enunciado, fenómeno o situación de cualquier naturaleza; es preciso comprenderlo. La comprensión va más allá del procesamiento y entendimiento psicológico, se extiende a la esfera experiencial personal y sociocultural, y a la vivenciación del objeto, teniendo en la reflexión consciente, crítica, metacognitiva y autorregulativa un acto que acompaña todo el proceso. No solo comporta el procesamiento cognitivo, metacognitivo y afectivo; la experiencia reflexiva y operativa de generar y usar los conocimientos o alcances comprensivos abraza nuevos sentidos y permite resignificar el objeto de comprensión, sea un texto o discurso escrito, oral, verbal o no verbal, resignificando y revalorizando también la existencia.

De esta manera, la comprensión se entiende como el mecanismo cognitivo, afectivo, reflexivo y vivencial por el cual se procesa una información relativa a objetos reales, ideales o imaginarios para convertirla en conocimiento consciente y resignificado como pensamiento en acto en contextos diversos que incluyan la experiencia personal y social del comprendedor (Arboleda, 2011a.; 2013; 2015b). El proceso comprensivo (pensamiento en acción) no es rectilíneo, pues independientemente de los equipajes personales las actuaciones y grados de comprensión surcan caminos de avances y retrocesos ${ }^{6}$; en general depende de las

$6 \quad$ Autores como Pushe (2018), entre otros reafirman esta idea de percibir, más que procesos cognitivos cambios cognitivos, y más que periodos transiciones; ponen 
circunstancias y de las condiciones de sujeto y contexto; del sujeto, porque, entre otras razones la índole diferencial de cada individuo supone no solo que este posee ritmos y estilos singulares, y que algunos están en mejores condiciones psíquicas para comprender, mientras que otros carecen por diversos motivos y en cierta medida de algunas o muchas de estas, por ejemplo la motivación, las operaciones, estrategias y representaciones; del contexto, porque igualmente algunos no poseen las condiciones educativas, entre otras haber sido afectados por ambientes y enseñanzas escolares y familiares para el aprendizaje y la comprensión, y porque un conocimiento se puede procesar y aplicar mejor en unos contextos que en otros. La evolución humanizada del sujeto pasa por la comprensión, pero demanda asimismo una comprensión otra ${ }^{7}$, y por ello una pedagogía otra ${ }^{8}$ y una enseñanza otra ${ }^{9}$.

de presente que el cambio cognitivo en los funcionamientos inferenciales implicados en la resolución de algunos problemas no sigue una trayectoria frontal de avances progresivos y secuenciales.

$7 \quad$ La CE hace parte de las perspectivas de la educación y la pedagogía que emergen para intervenir bajo principios sentidos en el acto educativo. De esta manera la comprensión cumple un rol más sensible en la visualización consciente, deliberada y actuante del mundo en su complejidad. Va más allá de su potencial como pensamiento actuante (y no por ello invulnerable) edificador, es decir constructor de vida más humana.

8 La PCE inaugura una pedagogía otra: la Pedagogía Comprensivo edificadora (Pce). Es esta una pedagogía otra en tanto la otredad erige su independencia de la episteme moderna basada en la razón (léase también, la comprensión) al servicio de la barbarie capitalista, que también agrega a la pedagogía, el desarrollo del conocimiento, del saber, de la ciencia, la cultura y la producción. Una episteme aliada a los fines de desarrollo económico y financiero más allá de los fines del desarrollo humano auténtico. La Pce es el campo del saber que estudia la educación como acción edificante de la vida humana y planetaria. En su acercamiento advierte las limitaciones y excesos a los cuales ha sido sometido el acto y aporta nuevas reflexiones y estrategias para su redireccionamiento y conducción bajo principios sustentados en la alteridad ética, en la humanización de las relaciones del hombre consigo mismo, con lo otro y con el otro.

9 La PCE asume la enseñanza como el campo en el que se articula la conservación del conocimiento históricamente constituido, en su encuentro con las dinámicas de la inestabilidad y la contingencia que le son constitutivas, y que llamamos saber (Behares, L. E, 2016), y por otro, como disciplina que ha de escudriñar y concurrir, con la función de educar como horizonte, en la aplicación, generación y uso razonable (personal, social y ecosistémicamente fiable) de conocimientos, saberes, conceptos, valores y actitudes (Arboleda, 2019). La segunda acepción
Expuesto de manera sucinta el concepto comprensión, es preciso señalar que la Pce aporta un nuevo concepto relativo a una forma de comprensión más compleja que enriquece las representaciones mentales que forman los comprendedores y que estos deben integrar para construir mayores significados y sentidos: la comprensión edificadora $(\mathrm{CE})^{10}$. Se trata esta de un nivel de comprensión en virtud del cual se usan generosamente las comprensiones, haciendo del pensamiento un acto que humaniza. Es un nivel integrador e íntegro del acto formativo: se traduce en comprensión consciente, cognitiva, generativa, crítica, reflexiva y ética, y también es transformador y redentor del sujeto y del contexto en tanto emerge de la necesidad de asumir la educación como acontecimiento de responsabilidad ética con el otro y lo otro. Al vivir la experiencia edificadora el comprendedor se humaniza ganando rasgos de otredad: es otro mejor para sí mismo y para lo otro y el otro con los cuales se entrelaza en la existencia; se redime de la monotonía inconsciente, no consciente o consciente de sí mismo, de la ausencia de otredad, y arriba a la consciencia de ser siendo, conduciendo la metamorfosis y constitución de su propio yo $\mathrm{o}^{11}$; corresponder al

representa una contribución de haría de la enseñanza una acción genuinamente educativa, otra.

10 Este nivel de comprensión se aplica igualmente a los procesos de lectura y escritura. Desde la PCE hemos propuesto el nivel edificador (Arboleda, J. C., 2016), complementario a los niveles literal, inferencial y crítico que se reconoce en el escenario comprensivo y discursivo. "Para que opere este nivel comprensivo es necesario que acaezcan movimientos interconectados aunque no lineales de desempeños de tipo cognitivo- conceptual y operativo edificador de sí mismo, del otro y de lo otro, pasando por la contemplación activa como ejercicio ontológico y axiológico, y la reflexión crítica y propositiva de la realidad y sus circunstancias, o lo que supone Godino y otros (2012) en su teoría de la identidad didáctica: "una reflexión sobre lo que hace con relación a lo que piensa".

11 En la perspectiva ética de la alteridad el yo es originariamente inclusivo. No ha madurado como yo quien no ha podido salir de su mismidad para responder del otro. El sujeto humano es también social, cultural y ambiental porque para vivir necesita del otro y lo otro. Para decirlo con Levinas (1977), "Ser yo significa, por lo tanto, no poder sustraerse a la responsabilidad". El crecimiento dimensional del sujeto robustece el yo que obedece incondicionalmente a la demanda fundacional del otro y lo otro. La responsabilidad ótrica es el termómetro de la construcción del sujeto sentipensante, comprensivo edificador. 
otro eleva el yo a una categoría de ascenso como persona humana, contrariamente el encumbramiento de mí mismo es condición de disminución y carencia de yo.

En tanto permite usar el saber con sentido edificante en el contexto de la vida personal del comprendedor y de la vida social, humana y planetaria, la CE humaniza, permite sabernos seres que afirman el tejido planetario, el enlace entre el mí mismo, el otro y lo otro. Sin este nivel la comprensión limita, es insuficiente para la evolución del educando como persona; lo deja a medio camino, en situación de fragilidad, a merced del orden financiero, antropocéntrico y totalitario que consume conocimiento y degrada vida. Para que opere una CE el sujeto debe haber logrado cierto grado de apropiación comprensiva de conocimientos y saberes, y ha de corporizar valores y actitudes para obrar éticamente con sus comprensiones. Es esta la comprensión que magnetiza la función de educar por y para la vida, que otorga sentido pleno a una enseñanza verdaderamente educativa; las comprensiones educativas constituyen retos y desafíos inminentes en la agencia de educar e imperativos incondicionales, (expresión de Levinas, 1977), en la función de educar. El acto de educar descansa sobre la comprensión afectiva y edificadora del otro y de la vida; el otro nutre el acto en tanto se revela como necesitado que el educador y las enseñanzas que educan advierten, persiguen y hospedan en el viaje formativo.

Es esta una comprensión sentida, es decir con sentido edificante; porque también reinan las comprensiones insensibles que basamentan proyectos de muerte. Como se sabe, el mundo de hoy promueve enseñanzas para saber y saber hacer, más que para saber ser, que pasan por intervenir en los procesos de apropiación y aplicación eficientista, más que comprensiva y ética, de conocimientos, saberes, disposiciones, valores y actitudes; agencias focalizadas hacia el saber hacer como potencial que asegure la producción de bienes para un consumo frenético como el que espera un mercado laboral que en razón de la rentabilidad financiera devasta vida humana y cósmica ${ }^{12}$. En esta dirección la comprensión puede ser orientada para limitar o para afirmar la vida. La PCE apuesta por la humanización de la comprensión de modo que fortalezca aquí, ahora y siempre actitudes, proyectos de vida y no proyectos de muerte, es decir de erosión de la vida; que toque pedagógicamente al educando, y lo sepa rozado con la yema de los dedos en su rostro ávido.

La comprensión edificadora es ética, es una comprensión ética ${ }^{13}$ en tanto pone los potenciales comprensivos al servicio responsable del otro, del ser humano y de la vida, y no exclusivamente al abandono de una productividad y rentabilidad deshumanizantes, que nos confina en la cárcel del sí mismo. Usar los conocimientos con sentido utilitarista, personal, egocéntrico, por encima del bien social y humano es contradictorio con los fines originales de la comprensión que tienen que ver con su uso "útil en la sociedad que le rodea" (Jiménez, 2014), mejor un uso al mismo tiempo para el bien personal y común, un uso solidario, si se prefiere planetario, que edifique, que humanice. La apropiación social del conocimiento globalizado representa un faltante ético, conlleva la posibibilidad de un uso malsano del mismo, que por el contrario despersonalice; es diametralmente opuesta a $12 \quad$ Interpolando a Serres en alusión a los saberes y la escuela, aquellos siguen afirmándose como oferta, más no como demanda. Unos y otros deberían responder a los desafíos primarios de la educación, "escuchando el ruido de fondo surgido de la demanda, del mundo y de las poblaciones" (2012, P. 55).

13 La comprensión ética (y aún la comprensión), como uno de los postulados de la perspectiva en referencia, constituye un ausente radical tanto en la pedagogía y la didáctica como en la enseñanza y en el aprendizaje. Para que una comprensión revista carácter ético precisa imprimir de humanidad el saber hacer de los comprendedores, sea el didacta, el metodólogo, el directivo, el enseñante o el educando; de lo contrario estaremos ante una comprensión técnica, importante sí en la cotidianiidad y en los procesos de aprendizaje, más deficiente para los procesos sustanciales que demanda el acto de educar y la educación. 
una apropiación comprensivo edificadora ${ }^{14}$. La comprensión éticamente edificadora es, como toda comprensión, analítica, interpretativa, crítica, reflexiva, generativa y vivencial, pero además es responsable, es decir al usar sus comprensiones el sujeto deja que aflore el otro que llevamos por dentro, y no ha de atentar contra sí mismo, el otro y lo otro incluido el entorno humano y los ecosistemas. Si gana ribetes de comprensión ético estética, la responsabilidad del ser aparcaría también en el despliegue de imaginación creadora que precisa vivir de modo más humano.

Vista así, la CE representa el potencial que exhibe el educando en su nuevo nacimiento como persona, según se expone a continuación. Es el colofón del acogimiento. Se podría decir que el educador reafirma su función de brindar enseñanzas que eduquen a medida que sus pupilos realizan actuaciones comprensivo edificadoras, en tanto los concibe, gesta y ve nacer de su propio vientre formativo con esas condiciones, potenciando, vitalizando en el proceso su propia subjetividad pedagógica, humana, otra ${ }^{15}$.

La PCE aporta conceptos teóricos y prácticos que proveen a educadores y educandos de equipajes para pensar y progresar, más que en competencias (saber hacer para el orden global), en comprensiones, es decir en saberes y potenciales por y para la vida, que edifiquen desde el acogimiento como principio pedagógico ${ }^{16}$.

La pedagogía ha dejado de acompañar al educador y al educando en los procesos formativos, reduciendo su papel a reflexionar y proponer medios para fortalecer enseñanzas y apropiación de saberes, de modo que los

\footnotetext{
$14 \quad$ Arboleda, J. C. (2019c).

$15 \quad$ Ya el hecho de concebir en su vientre formativo al estudiante como educando es un modo de saber ser educador, justamente cuando vive el ritual de acoger, "se hace responsable del otro, responde a este en su situación, se preocupa y ocupa de él desde la responsabilidad"
}

Arboleda, J. C. (2013). sujetos de este acto sean más competentes a la hora de construir y aplicar conocimientos. Extraviada de su finalidad humanizante expresada en la responsabilidad de educar y de vivir $^{17}$, la educación media en la formación de sujetos eficientes que precisa el mundo global del mercado, arrastrando a la pedagogía y los saberes educativos hacia esta empresa. Frente a esta alteración pedagógico educativa la PCE funge como uno de los constructos que participan activamente en la reorientación de unos y otros hacia movimientos auténticos.

\section{EL ACOGIMIENTO COMO PRINCIPIO: DEL PACTO AL PARTO PEDAGÓGICO}

Hay un pacto implícito en el movimiento de la educación y la pedagogía hacia el desarrollo. Consiste, como hemos señalado, en orientar este a la luz de los postulados del progreso y al margen de los principios originales de la formación ${ }^{18}$. En ese descarrío la pedagogía en particular se anega en el aprendizaje y escinde la función de educar. En el pacto originario de querer y saber acoger y acompañar al educando se traslapa el pacto competitivo de promover aprendizajes para la prosperidad financiera más no para una vida y existencia dignas. El movimiento auténtico del saber y la acción pedagógica estriban en generar abordajes para que las enseñanzas formen personas con potenciales comprensivo edificadores para erigir proyectos de vida que desemboquen en cuidado y evolución de sí mismas: y evolución de sí mismo, del otro y de lo otro. Este ejercicio hace inexcusable la refundación del pacto pedagógico y se representa a través de la metáfora CE del

$17 \quad$ La educación es, para decirlo con Bárcena y Mèlich (2000), citado por Arboleda (2019c), "un acontecimiento ético por el que el educando es re-conocido y abrazado en su singularidad". Donde el maestro se sepa afectado en su conciencia por el reconocimiento de los otros en sus circunstancias tempo espaciales, personales, concretas, y actúe en correspondencia, situadamente.

18 Para decirlo con Ortega y Romero, 2013, 66, "en pedagogía ha habido un silencio cómplice sobre los problemas y situaciones que dañan gravemente la dignidad y la libertad de nuestros conciudadanos, víctimas de la exclusión social, pobreza, xenofobia, fundamentalismo religioso, nacionalismo totalitario". 
parto pedagógico formativo en virtud de la cual nace un educador y un educando auténticos.

La refundación del pacto pedagógico consiste en repensar el sentido de la educación y la pedagogía, y asumir la función de educar en los procesos de enseñanza y formación ${ }^{19}$. Concebir docentes y agentes educativos (del estado, de las instituciones, los sistemas educativos, las agencias internacionales, directivos educativos) con actitud acogiente y comprensivo edificadora, y educandos sentipensantes, son dos grandes desafíos de la educación y la pedagogía para que aquellos tengan una participación digna en la evolución de la vida, que supone un parto pedagógico formativo ${ }^{20}$, como le hemos venido denominando al acto de labrar la actitud que han de manifestar los intervinientes en la formación y los aprendizajes comprensivo edificadores que ha de ofrecer la escuela para cumplir con la finalidad educativa fundamental, más preciada; un parto doble: en el seno de la institucionalidad y en el cuerpo concreto del aula, en el cara a cara docente y estudiante; uno institucional y otro áulico.

En el primer parto, el saber y la acción pedagógica han de motivar (diseñar) ambientes para que la institucionalidad política genere acciones y direcciones en las que se formen profesionales que enseñen educando ${ }^{21}$. Tal 19 De acuerdo con Ortega (2013), se trata de un pacto en torno a la "reubicación" del profesor, que le permita invertir sus prioridades y sus papeles como agente de la enseñanza; que lo sitúe en un escenario distinto y lo coloque en una "situación ética" en la que el alumno deje de ser objeto de "conocimiento y de control" para convertirse en interlocutor necesario en su proceso de construcción personal. 20 Arboleda, J. C. (2020) Enseñar educado: hacia una didáctica comprensivo edificadora. Editorial Redipe.

$21 \quad$ Las enseñanzas educativas son aquellas basadas en el acogimiento y en el acompañamiento del educando en el proceso de formación de consciencia y de comprensión edificante de sí mismo, del otro y lo otro que componen la existencia. Las enseñanzas que aspiran solamente a la construcción y uso de saberes no son educativas aún si intentan hacerlo desde el acogimiento. En principio las enseñanzas de saber y saber hacer no educan porque no hacen parte de una intencionalidad comprensivo edificadora, es decir sentida, con propósito humanizante. Para diseñar ambientes de aprendizajes por competencia se requiere en cierta medida de acciones acogientes relacionadas con reconocer en el otro parte de su condición psicológica, social y cultural. Pero este es un acogimiento a debe, insensible si se estima. Esta forma de acogimiento ha de dar lugar a la responsabilidad parto en el seno institucional precisa orientar formaciones bajo principios pluriversos de cuidado y respeto al complejo interrelacionado y activo de seres vivos y no vivos (personas, culturas, seres inorgánicos, etcétera) que constituyen la existencia. Formar, gestar educadores en potencia y en ejercicio como mejores ciudadanos del pluriverso e idóneos procreadores de educandos comprensivo edificadores.

Sólo alcanzan a emerger los docentes educados que logran apropiar el acto de educar como un parto edificador, cuando desean y se preparan para "concebir" en su propio seno al otro del rostro herido (Levinas) urgido de educación, dispuestos a reaprender de manera permanente para reconocerlo en su unicidad e intervenir de modo idóneo en la construcción cognitiva, metacognitiva, operativa y personalizante de conocimientos, en la formación de valores y actitudes por la vida -- no justamente para el mundo de hoy, inmensamente reluctante en calidad de vida --; para hospedarlo y habitarlo en su fragilidad y necesidad, sentirlo como su propia piel, protegiéndose a sí mismo, sin dejar de observar y analizar el proceso de manera consciente y crítica, propositiva y actuante ${ }^{22}$. En síntesis, la institucionalidad educativa, respetuosa de la alteridad obrará de modo tal que logre gestar un nuevo educador capaz de tocar pedagógicamente al educando e introyectarlo en su propio yo. Un yo incluyente, que en virtud de relaciones pedagógicas de otredad, de enseñanzas que eduquen para el cuidado de sí mismo, del otro y de lo otro, permita concebir, a su vez, una nueva criatura con sentimiento y conducta ciudadana, lo que solo será posible si el educando advierte al educador como un cómplice, un amigo franco, comprensivo y leal que lo reconozca en su diversidad y acompañe hasta donde pueda en

ética de acoger al estudiante en su singularidad de existencia y acompañarlo hasta donde sea posible en su nacimiento como educando necesitado de los potenciales pluridimensionales que le permitan ser cada vez más humano. $22 \quad$ Arboleda (2015b) 
su proceso de aprendizaje y formación humana.

Educar en la comprensión humana, en la formación de actitudes por y para la vida, impone un acogimiento situado y visceral. El acogimiento pasa por reconocer hasta donde sea posible al estudiante en su diversidad única, a saber: sus conocimientos previos, intereses, sentimientos, contexto, ritmos y modos de aprender, generar ámbitos para acompañarlo en el afrontamiento de sus carencias y en el decurso, fortalecimiento yuso de potenciales necesarios para el desarrollo de "representaciones mentales integradas (Trites \& McGroarty, 2005)" y actuaciones que gravitan en la comprensión. Pero también es primario en el acto (léase, en el pacto) de acoger la empatía y la disposición a cargar con el educando comprendedor, entronizarlo en el yo del educador como condición para educar con arte en la enseñanza. Pues una enseñanza sin entronizamiento del educando, no educa, no aporta a la formación para una vida más humana ${ }^{23}$.

Entronizar pedagógicamente estriba en hospedar y acompañar al educando hasta donde sea posible en la aventura de ser más humano. Ello requiere acariciar su "alma" para merecer residir como cómplice en ésta. El toque humano otorga confianza, motiva, dispone, construye docencias y discencias para la mayoría de edad humana; sin este no hay acogimiento, y si no hay recibimiento no hay entronizacion pedagógica. No hay educación verdadera, es decir para la evolución de la vida

Dado que son remotas las probabilidades de que la institucionalidad se sensibilice por sí misma con la condición de educabilidad -

23 La enseñanza solo es enseñanza si educa. Para decirlo con Comenio, siguiendo a Runge P., A. Klaus (2013), "no hay enseñanza que no eduque en algo". Estas premisas motivan la presencia en la PCE de la metáfora "enseñar educando" que constituye un principio pedagógico faltante en el universo educativo, pedagógico y didáctico. Toda buena enseñanza educa en algo, es decir apoyar al estudiante en la formación de algunos potenciales, para vivir y proceder en las relaciones sociales es ya un aporte en las posibilidades de ciudadanía. Pero ello, como hemos dicho, no es suficiente para ser ciudadano del pluriverso. enseñabilidad, es necesario reconocer que los cambios educativos parten del ejemplo y la acción personal. La institucionalidad no favorece cambios viscerales para el reencuentro de la educación con su finalidad primigenia de formar mejores personas. La función de educar ha sido prácticamente borrada del discurso y currículo por competencias, y por supuesto de las prácticas formativas basadas en estos, erosionando el ser de la educación. Por lo que, extrapolando a Levinas (1977, Pag 51), "es necesario una relación original y originaria con el ser", valga decir, reorientar la enseñanza y la educación a partir de principios anclados en el ser.

Está en los mismos docentes comprometidos con la función de educar, y en las nuevas criaturas que estos logren "concebir y alumbrar", así como en los sectores y organizaciones sociales consecuentes con una educación y una vida más humanas, forzar políticas educativas más edificantes, y promover sin cesar enseñanzas que eduquen en lugar de enseñanzas ancladas en aprendizajes para el rendimiento y la eficiencia bajo parámetros globalizados. Valga insistir en la necesidad imperiosa de que la educación y la pedagogía se ocupen del hombre, de la vida y la existencia, en lugar de responder a los sistemas opresivos que dominan sobre todas las cosas; y representen el fulgor que asegure una consciencia comprensiva actuante capaz de enfrentar con vigor al todopoderoso feroz y salvaje -- el unicornio, al decir de De Sousa S., B. (2020), -- que constituyen estos sistemas de poder que atentan, a expensas de la ignorancia, contra la humanidad y el planeta, y cuya omnipotencia parece ser "el espejo de la incapacidad inducida por los humanos para luchar contra ellos".

Esa sería una posibilidad magnífica de educar para un genuino desarrollo humano, mejor para la evolución de la vida humana y planetaria. De contribuir a la gestación de seres, 
docentes y educandos que se insubordinen a la normalidad y la costumbre impuestas, y obren como ciudadanos del pluriverso, que participen activamente en la construcción de mejores relaciones para un desarrollo social, económico, histórico, educativo, político, tecnológico, científico, ambiental, laboral y cultural que no vaya en contravía sino que asegure una vida y existencia más dignas.

La continuidad de la vida humana en el planeta depende de la humanización de la vida planetaria constituida por entes vivos y no vivos, de la forma como piloteemos, no sin el concurso de la educación y los saberes inherentes a la misma, un desarrollo humano planetario. Allí seguramente refulgen emergencias como la pedagogía y la didáctica comprensivo edificadoras.

La pedagogía debe retomar su camino edificante sin los lineamientos de los sistemas socioeconómicos que aupan al dinero y el rendimiento como las mayores aspiraciones, y resituar, relocalizar su acción sobre los hombros de una episteme comprensivo edificadora, volver su mirada y dinámicas al fundamento de la educación: formar mejores seres humanos, capaces de conducir bajo principios de respeto y protección sus relaciones consigo mismos, con el otro, con la vida y la existencia. $Y$ hacer de la didáctica y la enseñanza espacios para la apropiación democrática del saber con sentido de mundo común, prácticas para el saber ser, para el uso del saber a favor de todo aquello que afirme y no niegue la vida ${ }^{24}$.

$24 \quad$ Para ello es necesario también, valga retomar a De Sousa S., B. (2020, p. 84), "un giro epistemológico, cultural e ideológico que respalde las soluciones políticas, económicas y sociales que garanticen la continuidad de una vida humana digna en el planeta". Sobre el particular en el plano educativo, pedagógico y didáctico la PCE apuesta por una episteme comprensivo edificadora, libre de la colonización que ejercen las epistemologías modernas que siguen patrones de rendimiento y no los vaivenes de la evolución de la vida y la existencia humana. Observar y asumir teórica y metodológicamente este aspecto en la didáctica, haría quizás de este saber una praxis sentidamente transformadora, menos competente y más educativa, promotora de comprensiones sentientes como propulsores de crecimiento humano.
La crisis confinatoria ha mostrado la vulnerabilidad y perversidad del orden económico que domina y se instala, movilizando absolutos, en las relaciones sociopolíticas, que beneficia cada vez más a los corruptos y al gran poder financiero y político en mutua connivencia, y nos ha puesto a pensar en ello, en el peso del egoísmo y el individualismo presentes en este modo de relación, pero asimismo en nuestro descuido de la naturaleza y la vida misma hasta el grado en que ambas actitudes ahondan el deterioro humano y planetario. Allí la pedagogía y la didáctica serían útiles para incrementar, bajo una mirada más humana y menos ególatra o digamos egoepistémica, esta autoobservación y consciencia de vida y de lo que estamos siendo, y lograr desarrollar formaciones que impulsen consciencias edificadoramente actuantes. Más que imaginar una nueva pedagogía para las crisis humanas (políticas, económicas, sanitarias, ambientales, culturales, etc.), es preciso reconocer las perspectivas pedagógicas que enfilan saberes teóricos, técnicos y práxicos para el ejercicio formativo que prepare para proceder, con sentido humano, en la dinámica compleja de la vida, que hemos intentado caracterizar aquí, en razón de enriquecer las intervenciones en circunstancias determinadas. La pedagogía se reafirma justamente en las crisis, con la capacidad de los actores educativos para tramitar desde perspectivas situadas los principios pedagógicos más edificantes.

Si la educación no se realiza desde el principio de alteridad y los valores más democráticos, será un acto que acaso desarrolle enseñanzas y aprendizajes para saber - hacer, pero que de este modo nunca jamás podrá educar, pues educar, formar al educando como mejor persona, es la sustancia de toda educación y pedagogía, sea física y/o virtual. El reto educativo, tanto desde el aula presencial como la virtual, reside en que el estudiante se pueda saber sentir acogido, habitado en el yo del educador, escuchado, atendido, acompañado 
en su nuevo nacimiento o transformación como otro, como mejor ser humano y artífice de mundos más dignos, reconocido en su singularidad y pluridimensionalidad, en su realidad concreta histórico- cultural de sujeto necesitado, con sus fortalezas y dificultades, con sus intereses, sueños y miedos, motivado, tocado pedagógicamente. Pero ninguna de estas aulas y menos la segunda dan, en general, muestras de ello; si la interacción presencial no logra este cometido, menos lo hará un aula absolutamente virtual. Esta última no puede ofrecer más que mediaciones y artefactos basados, como se ha mencionado aquí, en protocolos estandarizados, propios de lógicas eficientistas y por ende homogenizantes o dessingularizantes, que buscan resultados que aseguren rentabilidad, lo cual excede los propósitos originales de la educación.

La pedagogía y la didáctica cumplen su finalidad al generar oportunidades y capacidades para aportar al proyecto humano de la vida, al fortalecimiento de los lazos más humanos entre los hombres, para el cuidado de la naturaleza, de los seres vivos y no vivos, de los ecosistemas en su devenir interconectado, asimétrico, contingente, y de ese modo enfrentar el proyecto inhumano y antropocéntrico de colonización y homogeneización planetaria, pluriversal.

En razón a la desorientación y deslocalización que viven la educación y las ciencias de la educación, es necesario generar y fortalecer perspectivas pedagógicas y didácticas más edificantes, perspectivas humanizantes, comprensivo edificadoras que hagan de la eficiencia, el rendimiento y los aprendizajes apoyados en la tecnociencia y basados en el saber hacer, prácticas con sentido de vida, de afirmación del saber ser, de un progreso social y económico que abone de verdad al crecimiento y desarrollo personal, cultural y ecosistémico. Que promuevan las enseñanzas que educan, enseñanzas para saber ser mejor gente, habitante digno del mundo vivo y no vivo.

Quizás de esa manera la educación, la pedagogía y la didáctica arrojen luces a la gestación, retomando los mejores legados y experiencias, de una nueva escuela, de un nuevo hombre, de una nueva humanidad que nos reconcilie con el pluriverso.

\section{A MODO DE CONCLUSIÓN}

La educación por y para la evolución de la vida precisa suscitar ambientes para acoger al otro y lo otro, provocando en el estudiante un nuevo nacimiento como sujeto y ciudadano del pluriverso, capaz de generar y apropiar adecuadamente saberes y conocimientos para el crecimiento de sí mismo, el desarrollo de la vida y la existencia. Ello supone una mirada otra, distante del paradigma moderno de comprensión de la pedagogía, que ve en esta una aliada para formar sujetos para el mundo del mercado y no para el mundo de la vida, y que asume la apropiación de conocimiento con criterios de maximización financiera; una perspectiva actuante que advierta en la pedagogía un campo de saber que, más que responder a lineamientos del progreso, interpele, haga de su acción un laboratorio de reflexión propositiva sobre sí misma en relación con su sentido primario de mundo común.

Más que cognitiva y social, la generación y apropiación de conocimiento en el que participa la pedagogía ha de constituir una apropiación responsable con la vida y la existencia humana y planetaria. Dado que el individuo no solo hace parte de la sociedad "humana" sino que al conformar el complejo interconectado e interdependiente de formas, procesos, culturas, seres vivos y no vivos que constituyen el pluriverso, del cual el sujeto edificadoramente educado se hace ético, garante, habitante digno, la apropiación de conocimiento se ha de enmarcar en las relaciones tecnociencia 
y sociedad ecosistémica, mejor saber tecnocientífico y ancestral-pluriverso, y ha de revestir carácter comprensivo edificador. No se trata de formar sujetos para que respondan a las angustias del mundo del mercado, es preminente educar para formar ciudadanos que generen, construyan y usen conocimiento con sentido de otredad, es decir de responsabilidad ética frente a un espacio común. Se trata de saber generar-apropiar conocimiento bajo principios humanamente sensibles y no utilitaristas, y promover una socialización y uso sentipensante, que nos conecte con el planeta y la vida. Una auténtica apropiación comprensivo edificadora, civilizatoria, otra de conocimientos y saberes, que aporte a un genuino desarrollo humano, mejor, a la evolución de la vida humana y cósmica.

\section{REFERENCIAS BIBLIOGRÁFICAS}

Arboleda, J.C. (2005). Estrategias para la comprensión significativa. Editorial Magisterio, Bogotá.

Arboleda, J.C. (2007). Pensamiento lateral y aprendizajes. Ed Magisterio.

Arboleda, J.C. (2008a). Aprendizaje y comprensión: del enfoque de competencias al enfoque de comprensiones y proyectos de vida. Rev. Educación y Cultura, No 79.

Arboleda, J.C. (2008b). Aprendizaje por competencias, comprensiones y proyectos de vida personal y familiar, Editorial Penser.

Arboleda, J.C. (2011). Competencias pedagógicas: conceptos y estrategias. Bogotá: Editorial Redipe.

Arboleda, J. C. (2013). Hacia un nuevo concepto de pensamiento y comprensión. Revista Boletín Redipe (8/ 24).

Arboleda, J. C. (2015a). Formación para la vida: de las competencias a la comprensión edificadora, Revista Boletín Redipe. Vol. 4, №. 12, págs. $20-25$

Arboleda, J. C. (2015b) La pedagogía de la alteridad en la perspectiva de la comprensión edificadora. Revista Educación y pensamiento. P 46.

Arboleda, J. C. (2016). Textos académicos. Editorial Redipe.

Arboleda, J. C. (2019a). La educación es inclusiva. Perspectiva comprensivo edificadora de la formación. (Texto de la conferencia impartida por el autor en el Ciclo: La tarea crítica de la educación incluiva. Celei, Chile.

Arboleda, J. C. (2019b). Educación y proyectos de vida. Revista Lope De Barrientos. Seminario De Cultura, Ucm, España, No. 11.

Arboleda, J. C. (2019c). Pasivos y desafíos en la educación. Revista Boletín Redipe: 8 (4).

Arboleda, J. C., (2020a). Hacia una didáctica comprensivo edificadora. Uned - Redipe.

Arboleda, J. C., (2020b). Enseñar educando. Hacia una didáctica comprensivo edificadora. Editorial Redipe.

Bárcena, F. y Mélich, J. C. (2000). La educación como acontecimiento ético: natalidad, narración y hospitalidad. Barcelona: Paidós.

Behares, L. E (2016). La caracterización de la enseñanza como conjunto de técnicas para intervenir en los aprendizajes: un análisis crítico. Educação. Revista do Centro de Educação, vol. 41, núm. 3.

Ceballos E., E. - Puche N. Rebeca (2018). Funcionamientos Inferenciales en Niños Caminadores: un acercamiento al Microdesarrollo en una Tarea de Resolución de Problemas: Revista Colombiana de Psicología, Vol. 27, N. 2, págs. 117-135 
De Sousa Santos, Boaventura (2020). La cruel pedagogía del virus. Ciudad Autónoma de Buenos Aires : CLACSO.

Fairclough, N. (2008). El análisis crítico del discurso y la mercantilización del discurso público: Las universidades. Discurso \& Sociedad, Vol 2(1) 2008, 170-185

Didier Cariou, «DORIER Jean-Luc, LEUTENEGGER Francia \& SCHNEUWLY Bernard (dir.). Didactique en construction, construction des didactiques ", Revue française de pédagogie [En ligne], 190 | janvier-févriermars 2015, mis en ligne le 31 mars 2015, consulté le 05 janvier 2020. URL :

http:// journals.openedition.org/rfp/4726

Escobar, A. (2012). Más allá del desarrollo: postdesarrollo y transiciones hacia el pluriverso. Revista de Antropología Social, 21, p. 23-62

Gaete V., M (2015). Didáctica, temporalidad y formación docente. Revista Brasileira de Educação, v. 20 n. 62

Godino, J., Rivas, H., \& Arteaga, P. (2012). Inferencia de indicadores de idoneidad didáctica a partir de orientaciones curriculares. Praxis Educativa Brasil. 331-354.

Jiménez, E. (2014). Comprensión lectora vs. competencia lectora. Asociación Española de comprensión lectora, 1, 65-74.

Levinas, E. Totalidad e infinito. Ensayo sobre la exterioridad. Ediciones Sígueme S.A.U., 1977

Ortega R.P.(2020). Educar desde la experiencia del otro. Revista Boletín Redipe: Año 79 Volumen 2.

Ortega, P. y Romero, E. (2013) "La experiencia de las víctimas en el discurso pedagógico", Teoría de la educación. Revista Interuniversitaria, 25, 1, pp. 63-77.
Romero S., Eduardo (2012). Aproximación al concepto de responsabilidad en Lévinas: implicaciones educativas. Bordon, Revista Pedagógica. En Vol 44- 4.

Serres, M. (2013). Pulgarcita. Fondo de cultura Económca, Argentina. 